\title{
Fisionomia e estrutura de uma floresta estacional montana do maciço da Borborema, Pernambuco - Brasil ${ }^{1}$
}

\author{
LADIVANIA M. DO NASCIMENTO ${ }^{2,3}$ e MARIA JESUS N. RODAL ${ }^{2}$
}

(recebido: 05 de maio de 2005; aceito: 25 de outubro de 2007)

\begin{abstract}
Physiognomy and structure of a seasonal montane forest at Borborema massif, Pernambuco - Brazil). The physiognomy and structure of the tree component of a montane forest fragment located in an area at $900 \mathrm{~m}$ altitude ( $8^{\circ} 11^{\prime} 144^{\prime \prime}-$ $8^{\circ} 12^{\prime} 27^{\prime \prime} \mathrm{S}$ and $36^{\circ} 23^{\prime} 730^{\prime \prime}-36^{\circ} 24^{\prime} 638^{\prime \prime} \mathrm{W}$ ), with $948 \mathrm{~mm}$ of annual rainfall, and deep soil were studied. All alive or dead standing plants with diameter at breast height $\geq 5 \mathrm{~cm}$, within 50 contiguous plots, $10 \times 20 \mathrm{~m}$ each, had their trunk diameter, total plant height and canopy projection area measured. The species were classified in relation to their leaf size, deciduousness, and lamina composition. A total of 61 species were sampled plus one unidentified taxon. Plant density, basal area and average and maximum height and diameters were 1,553 plant ha ${ }^{-1}, 39 \mathrm{~m}^{2} \mathrm{ha}^{-1}, 10.3$ and $30 \mathrm{~m}, 14.2$ and $105 \mathrm{~cm}$, respectively. About $75 \%$ of all alive plants had between 1.4 and $3 \mathrm{~m}$ high. The distribution of basal and canopy areas according to height class indicated two ranges of plant concentrations: 7-13 and 19-22 m. The forest fragment represents a transition between humid and dry montane forests. Most of the species are evergreen with simple microphyllous leaves (Casearia sylvestris Sw., Guapira nitida (Schmidt) Lundell, Marlierea clausseniana (O. Berg) Kiaersk., Ocotea aff. elegans Mez, Plinia sp.), they occurred in the canopy of the forest, together with notophyllous species (Amaioua cf. guianensis Aubl. and Roupala paulensis Sleumer) and mesophyllous (Fabaceae sp. and Inga marginata Willd.). The emergent trees are mostly deciduous and compound leaf species, such as Copaifera trapezifolia Hayne and Eriotheca crenulaticalyx A. Robyns.
\end{abstract}

Key words - Brazilian Northeast, phytosociology, semi-arid, vertical structure

RESUMO - (Fisionomia e estrutura de uma floresta estacional montana do maciço da Borborema, Pernambuco - Brasil). Foi caracterizada a fisionomia e a estrutura do componente arbóreo de um fragmento de floresta estacional montana situado a

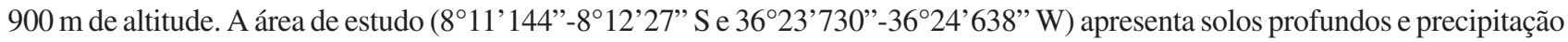
média anual de $948 \mathrm{~mm}^{2} \mathrm{ano}^{-1}$. Foram amostrados todos os indivíduos vivos ou mortos, ainda em pé, com diâmetro a altura do peito $\geq 5 \mathrm{~cm}$, em 50 parcelas contíguas de 10 x $20 \mathrm{~m}$, e tomadas as seguintes medidas: altura total, diâmetro do caule e área de cobertura da copa. As espécies foram classificadas quanto ao tamanho foliar, deciduidade e composição do limbo. Um total de 62 espécies (um taxon não identificado) foi amostrado. Densidade total, área basal total, altura e diâmetro médios e máximos dos indivíduos vivos foram 1.553 ind ha ${ }^{-1}, 39 \mathrm{~m}^{2} \mathrm{ha}^{-1}, 10,3$ e $30 \mathrm{~m}$ e 14,2 e 105,0 cm, respectivamente. Cerca de $50 \%$ dos indivíduos vivos ocorreram abaixo de $10 \mathrm{~m}$ de altura. A distribuição das áreas basais e cobertura de copa por classe de altura indicou dois intervalos de concentração: 7-13 e 19-22 m. A área representa uma floresta estacional montana de transição entre as florestas ombrófilas e estacionais. A maioria das espécies é perenifólia e apresenta folhas simples e micrófilas (Casearia sylvestris Sw., Guapira nitida (Schmidt) Lundell, Marlierea clausseniana (O. Berg) Kiaersk., Ocotea aff. elegans Mez, Plinia sp., entre outras), ocupando o dossel da floresta juntamente com espécies notófilas (Amaioua cf. guianensis Aubl. e Roupala paulensis Sleumer) e mesófilas (Fabaceae sp. e Inga marginata Willd., entre outras). Entre as emergentes predominam espécies com folhas caducifólias e compostas, como Copaifera trapezifolia Hayne e Eriotheca crenulaticalyx A. Robyns.

Palavras-chave - estrutura vertical, fitossociologia, Nordeste brasileiro, semi-árido

\section{Introdução}

Diferentes autores têm reconhecido que a maioria das florestas montanas neotropicais (1.000 a $3.000 \mathrm{~m})$ é preferencialmente ombrófila, embora haja registro de florestas montanas estacionais em locais com baixa

1. Parte da dissertação de mestrado da primeira autora, Programa de Pós-Graduação em Botânica da Universidade Federal Rural de Pernambuco.

2. Universidade Federal Rural de Pernambuco, Departamento de Biologia, Programa de Pós- Graduação em Botânica, Rua Dom Manoel de Medeiros s/n, 52171-900 Recife, PE, Brasil.

3._Autor para correspondência: ladivania@hotmail.com precipitação (Webster 1995, Richards 1996). Independente da umidade, esses dois tipos de florestas se caracterizam pela alta nebulosidade que, segundo Vogelmann (1973), é o fator responsável pela sua existência e manutenção.

A maioria das florestas montanas do Nordeste do Brasil (floresta serrana ou brejo de altitude) ocorre nos topos e encostas de serras do semi-árido, em altitudes que variam de 600 a 1.100 m (Vasconcelos Sobrinho 1970). Além disso, este autor observou que aquelas florestas apresentam diferenças fisionômicas e florísticas, em função do efeito de continentalidade, onde aquelas mais próximas do litoral estariam mais influenciadas pela flora das formações florestais litorâneas, enquanto as mais 
interioranas seriam mais relacionadas às florestas estacionais e xerófilas. Estudos quantitativos realizados por Tavares et al. (2000) e Ferraz et al. (2003) corroboram aquelas observações, uma vez que nas florestas montanas mais secas e interioranas aqueles autores notaram a ausência de espécies e famílias típicas das florestas montanas mais úmidas e próximas da costa.

Associado a questão da fisionomia e ou estrutura, diferentes autores têm argumentado a importância de se analisar os padrões foliares dos indivíduos, como mais um atributo fisionômico em sistemas de classificação de vegetação (Grubb et al. 1963, Werger \& Sprangers 1982, Richards 1996). Nas florestas neotropicais, nota-se que à medida que aumenta a altitude ocorre uma diminuição da área foliar, enquanto no interior da floresta parece haver uma tendência de diminuição ao longo de um gradiente vertical (Cain et al. 1956, Grubb et al. 1963, Popma et al. 1988, Richards 1996). Quanto a sazonalidade na produção de folhas em florestas neotropicais, Givnish (1978) observou que ocorre aumento da proporção de espécies decíduas com o aumento do déficit hídrico. Deve-se ressaltar a ausência desse tipo de dados nas florestas montanas nordestinas, tendo sido realizado apenas um trabalho em floresta estacional semidecidual de terras baixas (Andrade \& Rodal 2004).

Levando em consideração tais observações, é esperado que as florestas montanas pernambucanas situadas em áreas de transição, entre ambientes mais úmidos e mais secos, apresentem características fisionômicas e estruturais ora mais relacionados com as florestas ombrófilas montanas (Tavares et al. 2000), ora com as florestas estacionais montanas (Rodal \& Nascimento 2006). Com relação à morfologia foliar, é esperado que as florestas estacionais montanas apresentem menor área foliar que a registrada em estacionais de terras baixas (Andrade \& Rodal 2004).

Considerando que aquela condição de transição é encontrada na floresta estacional montana no Município de Brejo da Madre de Deus, Pernambuco, foi realizado o levantamento quantitativo do componente arbóreo e analisado o padrão foliar com objetivo de responder as seguintes questões: 1) Qual a fisionomia e estrutura dessa floresta? 2) Há diferenças florísticas e estruturais no componente arbóreo dos diferentes tipos de florestas montanas pernambucanas? 3) As características morfológicas foliares (tamanho, deciduidade e composição do limbo) respondem ao padrão das florestas tropicais?

\section{Material e métodos}

Descrição da área - O Município de Brejo da Madre de Deus está situado no Estado de Pernambuco. A sede do Município, localizada a $636 \mathrm{~m}$ de altitude, apresenta uma precipitação média anual de $948 \mathrm{~mm}$, com regime de chuvas de outonoinverno. O período de chuvas se estende de março a julho, apresentando um período seco $\left(<100 \mathrm{~mm} \mathrm{mês}^{-1}\right)$ de seis a oito meses, o que caracteriza o clima como tropical úmidoseco, com longa estação seca (Richards 1996). Todavia não existem dados pluviométricos para as áreas serranas deste Município, situado no planalto da Borborema.

De acordo com Lyra (1982), das serras do Município de Brejo da Madre de Deus, a do Bituri apresenta a maior cobertura florestal $\left(41 \mathrm{~km}^{2}\right)$, embora em fragmentos descontínuos. De acordo com o sistema de classificação de Veloso et al. (1991), a vegetação local é classificada como floresta estacional semidecidual montana. Rodeando a serra, nas cotas inferiores a $550 \mathrm{~m}$ de altitude, predomina uma vegetação não florestal caducifólia espinhosa, a chamada caatinga (Lyra 1982). Nas cotas mais elevadas da serra do Bituri, onde a vegetação florestal está presente, ocorrem solos profundos do tipo Podzólico Vermelho-Amarelo Orto, semelhantes aos encontrados nas áreas mais úmidas próximas da costa atlântica do Estado de Pernambuco (Jacomine et al. 1973).

Como área de estudo, foi selecionado um fragmento florestal da serra do Bituri, conhecido como Mata da Malhada ( $8^{\circ} 11^{\prime} 14^{\prime \prime}-8^{\circ} 12^{\prime} 27^{\prime \prime}$ S e $\left.36^{\circ} 23^{\prime} 73^{\prime \prime}-36^{\circ} 24^{\prime} 63^{\prime \prime} \mathrm{W}\right)$, abrangendo cerca de 150 ha e altitude variando de 900 a $1.030 \mathrm{~m}$. A área foi escolhida por apresentar o melhor estado de conservação entre os fragmentos visitados e caracterizase por apresentar um dossel aberto e bastante heterogêneo, onde se sobressaem indivíduos de Copaifera trapezifolia Hayne (Pau d'óleo). O sub-dossel é fechado com poucas ervas, lianas e epífitas, exceto em clareiras.

Coleta e análise dos dados - Durante 21 meses (1999-2000) foram realizadas excursões mensais para um trecho representativo da Mata da Malhada amostrando-se, a $900 \mathrm{~m}$ de altitude, um ha contíguo de vegetação $(20$ x $500 \mathrm{~m})$, subdividido em 50 parcelas de $10 \times 20 \mathrm{~m}$, incluindo os indivíduos vivos e mortos ainda em pé, com diâmetro do caule a $1,30 \mathrm{~m}$ de altura $(\mathrm{DAP}) \geq 5 \mathrm{~cm}$. De cada indivíduo foram registrados: DAP; altura total estimada; largura e comprimento de copa (Bongers et al. 1988, Popma et al. 1988). A cobertura da copa foi calculada de acordo com a fórmula de uma elipse (Popma et al. 1988).

O material coletado foi identificado por especialistas do Brasil e do exterior, auxílio de bibliografia especializada ou por comparação com material depositado nos herbários PEUFR (Herbário Professor Vasconcelos Sobrinho) e IPA. A coleção foi tombada no (PEUFR), seguindo o sistema de classificação de Cronquist (1981).

Em seguida, foram calculados parâmetros fitossociológicos de densidade, frequiência e dominância relativas e valor de importância, utilizando o pacote Fitopac (Shepherd 1995) e realizadas análises da distribuição vertical de vários parâmetros.

Os resultados do número de indivíduos por classes de altura $(3 \mathrm{~m})$ e área basal (em intervalo de $5 \mathrm{~cm}^{2}$ ) foram comparados a levantamentos com o mesmo critério de 
inclusão, em florestas ombrófilas de terras baixas (Siqueira et al. 2001, Silva \& Rodal dados não publicados), ombrófila montana (Tavares et al. 2000) e estacional montana (Rodal \& Nascimento 2006) de Pernambuco, através do teste de Kolmogorov-Smirnov a 5\% de probabilidade (Sokal \& Rohlf 1979).

Considerando que a literatura relata que a definição de estratos em florestas tropicais é bastante questionável (Richards 1996) e que depende dos critérios de quem estabelece os estratos, se com ênfase em folhagem, biomassa, espécies, etc. (Grubb et al. 1963), optou-se por analisar a distribuição vertical dos indivíduos, da área basal, do grau de cobertura das copas e espécies, composição da folha, tamanho da folha e deciduidade em intervalos fixos de classe de altura. Após serem testados diversos intervalos, optou-se pelo de $3 \mathrm{~m}$ por ser o que melhor representou a variação vertical observada em campo para os diversos parâmetros fisionômicos (densidade, área basal, cobertura de copa e características foliares).

Os tamanhos das folhas das espécies foram determinados medindo-se a área de 20 folhas maduras de sombra coletadas aleatoriamente de ramos de indivíduos adultos. No caso de folhas compostas, a média de área de 20 folíolos foi multiplicada pelo número total destes na folha. As folhas foram agrupadas usando o sistema de classificação Raunkiaer (1934) adaptado por Cain et al. (1956) (macrófilas $=182,25-1640,25 \mathrm{~cm}^{2}$, mesófilas $=45-182,25 \mathrm{~cm}^{2}$, notófilas $=20,25-45 \mathrm{~cm}^{2}$ e micrófilas $=2,25-20,25 \mathrm{~cm}^{2}$ ). As espécies foram ainda classificadas em porcentagem, quanto à deciduidade das folhas (perenifólias ou caducifólias), através de observações visuais, e quanto à composição do limbo (simples ou composta). Os resultados do tamanho de folha, deciduidade e composição do limbo foram analisados por espécie, considerando-se apenas o individuo mais alto amostrado.

Para análise da similaridade vegetacional da área de estudo com outras florestas ombrófilas de terras baixas (Barbosa 1996, Siqueira et al. 2001, Silva \& Rodal dados não publicados), estacional de terras baixas (Andrade \& Rodal 2004), ombrófilas montanas (Tavares et al. 2000, Ferraz \& Rodal 2006) e estacionais montanas (Ferraz et al. 2003, Rodal \& Nascimento 2006) da região foi elaborada uma matriz de densidade relativa das espécies, empregando o coeficiente de distância euclidiana média e o método de agrupamento de Ward, utilizando o programa PC-ORD 4.14 (McCune \& Mefford 1999).

\section{Resultados}

Fisionomia - Foram amostrados 1.553 ind ha ${ }^{-1}$ vivos e 104 ind ha $^{-1}$ mortos, correspondendo a uma área basal total de $39 \mathrm{~m}^{2} \mathrm{ha}^{-1}$. As alturas e diâmetros médios e máximos de todos os indivíduos foram: $10,3( \pm 4,6)$ e $30 \mathrm{~m} ; 14,2$ $( \pm 10,6)$ e $105 \mathrm{~cm}$, respectivamente. Na tabela 1 listam-se os valores dos parâmetros relativos à organização comunitária da área de estudo e de outros levantamentos realizados nas florestas de Pernambuco e Paraíba que utilizaram o mesmo critério de inclusão adotado neste trabalho, com exceção de Ferraz et al. (2003).

A distribuição dos indivíduos no espaço vertical (figura 1A-C) indica que: (1) a maior concentração de indivíduos ocorreu entre 4,1 e $13 \mathrm{~m}$; (2) cerca de $50 \%$ dos indivíduos apresentaram altura $\geq 10 \mathrm{~m}$; (3) cerca de
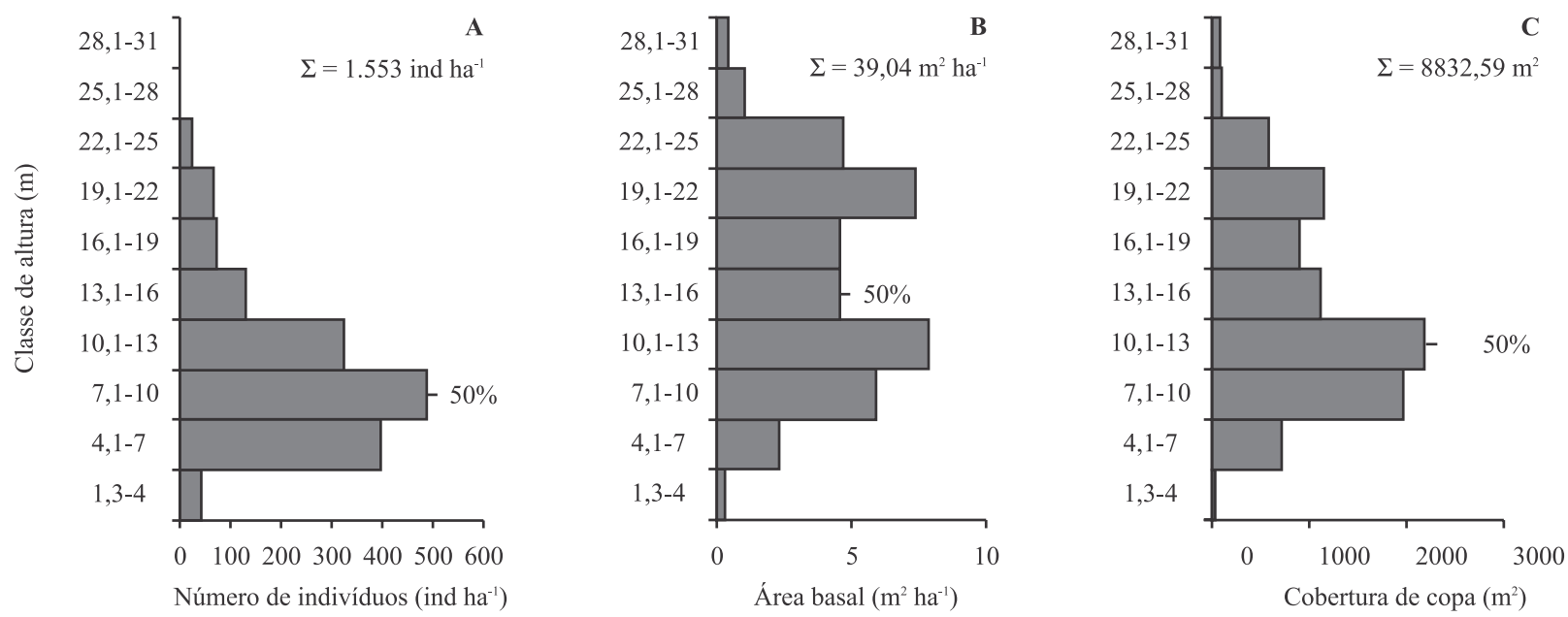

Figura 1. Distribuição vertical do número de indivíduos, ind ha- ${ }^{-1}(\mathrm{~A})$, área basal, $\mathrm{m}^{2} \mathrm{ha}^{-1}(\mathrm{~B})$ e cobertura de copa, $\mathrm{m}^{2}$ ha-1 $(\mathrm{C})$ em intervalos de classe de altura de $3 \mathrm{~m}$ dos indivíduos vivos amostrados num fragmento de floresta estacional montana no Município de Brejo da Madre de Deus, Pernambuco.

Figure 1. Vertical distribution of the number of individuals, ind ha-1 $(\mathrm{A})$, basal area, $\mathrm{m}^{2} \mathrm{ha}^{-1}(\mathrm{~B})$, crown coverage, $\mathrm{m}^{2}$ ha ${ }^{-1}(\mathrm{C})$ per height classes intervals of $3 \mathrm{~m}$ of alive individuals sampled at a seasonal montane forest fragment in the Brejo da Madre de Deus municipality, Pernambuco. 


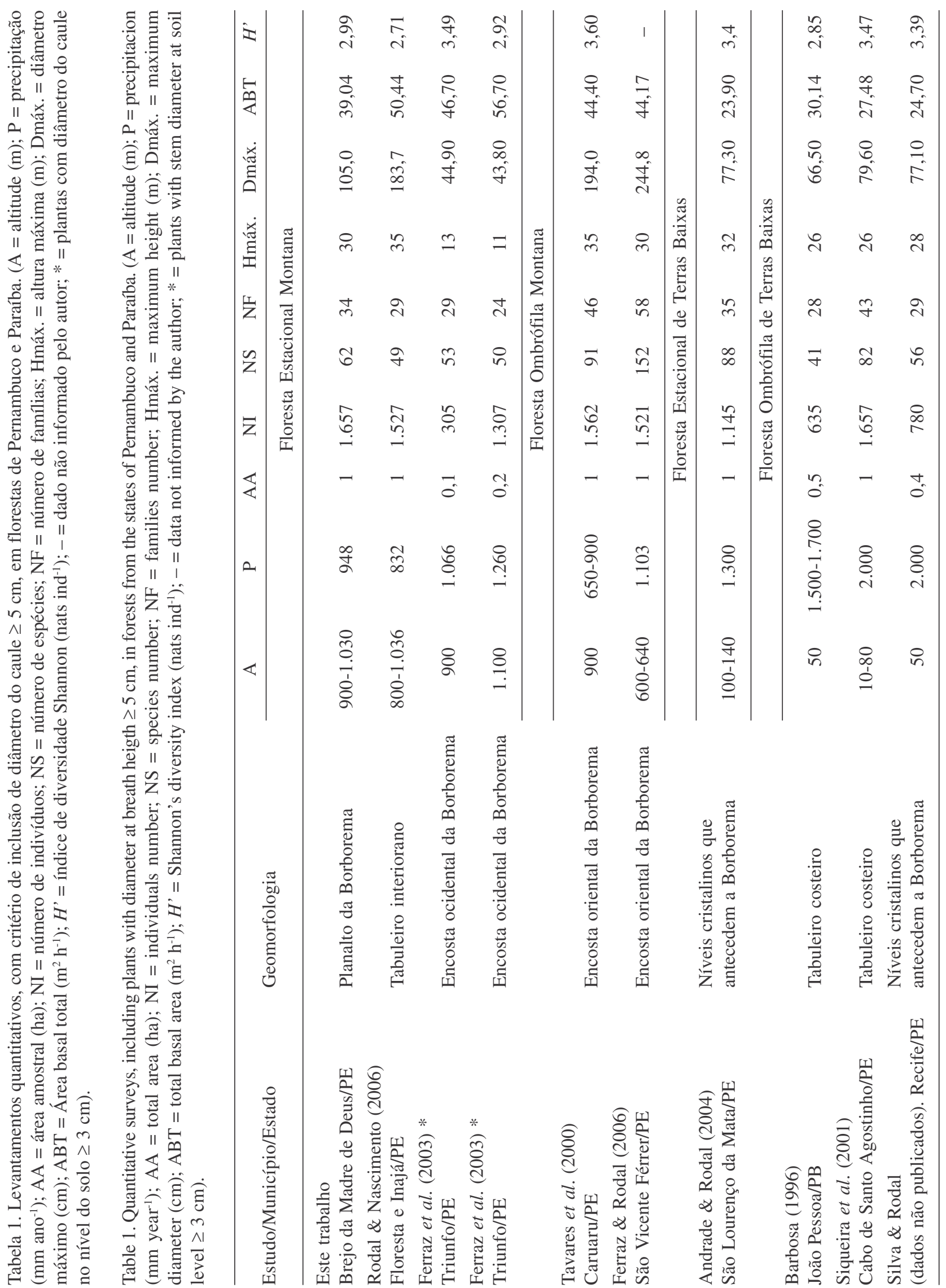


$50 \%$ da cobertura de copa é feita por indivíduos de até $13 \mathrm{~m}$ de altura; (4) mais de $50 \%$ dos indivíduos tiveram diâmetro do caule entre 4,7 e $10 \mathrm{~cm}$; (5) os indivíduos com até $15 \mathrm{~m}$ de altura responderam por $50 \%$ da ABT (área basal total); (6) a maior concentração da ABT ocorreu nas classes entre 10,1 a 13 m e de 19,1 a 20 m, com valores semelhantes; (7) os indivíduos acima dos 22 m contribuíram apenas com cerca de $9 \%$ da cobertura de copa, não chegando a formar um estrato fechado.

Os resultados acima indicam uma possível estratificação: um estrato inferior (abaixo de $13 \mathrm{~m}$ ), mais fechado em termos de cobertura de copas e, outro superior (acima de $19 \mathrm{~m}$ ), mais aberto. Como indivíduos emergentes podemos citar aqueles acima de $22 \mathrm{~m}$. Tais resultados confirmam a impressão visual de um dossel heterogêneo e aberto e um sub-dossel denso e fechado em termos de biomassa foliar.

Os resultados da distribuição do número de indivíduos por classe de altura e por classe de área basal em levantamentos em florestas de Pernambuco e da área de estudo (tabela 2), mostram que não há diferenças significativas entre elas, exceto no trabalho de Rodal \& Nascimento (2006), que se diferencia em termos de número de indivíduos por classe de altura.

Estrutura-Foram identificadas 62 espécies, pertencentes a 32 famílias (1 táxon não identificado) (tabela 3). O índice de diversidade de Shannon (para espécie) foi de 2,99 nats ind $^{-1}$.

Das espécies amostradas, 15 responderam por $75 \%$ do valor da importância total, destacando-se Guapira nitida com $26 \%$ de densidade relativa e $22 \%$ de dominância
Tabela 2. Teste de Kolmogorov-Smirnov para comparação entre distribuição do número de indivíduos por classes de altura $(3 \mathrm{~m})$ e de área basal $\left(50 \mathrm{~cm}^{2}\right)$ entre a área de estudo e outras florestas de Pernambuco 1 = área de estudo; $2=$ Tavares et al. 2000; 3 = Silva \& Rodal dados não publicados; 4 = Siqueira et al. 2001; 5 = Rodal \& Nascimento 2006; 1 , $5=$ Floresta estacional montana; 2 = floresta ombrófila montana; 3, 4 = floresta ombrófila de terras baixas.

Table 2. Kolmogorov-Smirnov test comparing the distribution of individuals' number per height $(3 \mathrm{~m})$ and by basal area $\left(50 \mathrm{~cm}^{2}\right)$ classes between the study area and other forests in Pernambuco 1 = study area; 2 = Tavares et al. 2000; $3=$ Silva \& Rodal in press; 4 = Siqueira et al. $2001 ; 5=$ Rodal \& Nascimento 2006; 1, 5 = seasonal montane forest; 2 = ombrophilous montane forest; $3,4=$ ombrophilous lowland forest.

\begin{tabular}{ccccccc}
\hline \multirow{2}{*}{ Levantamentos } & 1 & 2 & 3 & 4 & 5 \\
\cline { 2 - 6 } & \multicolumn{5}{c}{ Número de indivíduos / Altura } \\
\hline 1 & - & 0,166 & 0,147 & 0,109 & $0,240^{*}$ \\
2 & - & - & 0,080 & 0,101 & $0,356^{*}$ \\
3 & - & - & - & 0,098 & $0,292^{*}$ \\
4 & - & - & - & - & $0,333^{*}$ \\
& & \multicolumn{7}{c}{ Número de indivíduos / Área } & Basal \\
\cline { 2 - 6 } 1 & - & 0,074 & 0,073 & 0,088 & 0,173 \\
2 & - & - & 0,048 & 0,044 & 0,099 \\
3 & - & - & - & 0,077 & 0,121 \\
4 & - & - & - & - & 0,085 \\
\hline
\end{tabular}

* Valores significativamente diferentes ao nível de 5\%.

Tabela 3. Relação das espécies arbóreas amostradas no fragmento de floresta estacional montana no Município de Brejo da Madre de Deus, $\mathrm{PE}$, com seus parâmetros fitossociológicos e características foliares. ( $\mathrm{N}=$ número de indivíduos; $\mathrm{DR}=$ densidade relativa (\%); DoR = dominância relativa $(\%) ; \mathrm{FR}=$ freqüência relativa $(\%) ; \mathrm{VI}=$ valor de importância; $\mathrm{D}=$ deciduidade da folha; $\mathrm{P}=$ perenifólia; $\mathrm{C}=$ caducifólia; $\mathrm{CL}=$ composição do limbo; $\mathrm{S}=$ simples; $\mathrm{C}=$ composta; $\mathrm{TF}=$ tamanho da folha).

Table 3. Checklist of arboreal species sampled in a seasonal montane forest fragment in Brejo da Madre de Deus municipality, $\mathrm{PE}$, with their phytosociological parameters and foliar characteristics. ( $\mathrm{N}=$ number of individuals; $\mathrm{DR}=$ relative density $(\%)$; $\mathrm{DoR}=$ relative dominance $(\%) ; \mathrm{FR}=$ relative frequency $(\%) ; \mathrm{VI}=$ importance value; $\mathrm{D}=$ leaf deciduousness; $\mathrm{P}=$ evergreen; $\mathrm{C}=$ deciduous; $\mathrm{CL}=$ lamina composition; $\mathrm{S}=$ simple; $\mathrm{C}=$ compound; $\mathrm{TF}=$ leaf size).

\begin{tabular}{|c|c|c|c|c|c|c|c|c|c|}
\hline Família/Espécie & $\mathrm{N}$ & DR & DoR & FR & VI & Coletor e número & $\mathrm{D}$ & CL & $\mathrm{TF}$ \\
\hline \multicolumn{10}{|l|}{ ANNONACEAE } \\
\hline Guatteria sp. & 4 & 0,24 & 0,05 & 0,44 & 0,73 & L.M.Nascimento 231 & $\mathrm{P}$ & S & notófila \\
\hline \multicolumn{10}{|l|}{ APOCYNACEAE } \\
\hline Aspidosperma parvifolium A. DC. & 125 & 7,54 & 8,50 & 5,53 & 21,57 & L.M.Nascimento 303 & $\mathrm{C}$ & S & micrófila \\
\hline \multicolumn{10}{|l|}{ AQUIFOLIACEAE } \\
\hline Ilex aff. sapotifolia Reissek & 1 & 0,06 & 0,05 & 0,15 & 0,26 & L.M.Nascimento 151 & $\mathrm{P}$ & S & $\begin{array}{l}\text { micrófila } \\
\text { continua }\end{array}$ \\
\hline
\end{tabular}


continuação

\begin{tabular}{|c|c|c|c|c|c|c|c|c|c|}
\hline Família/Espécie & $\mathrm{N}$ & DR & DoR & FR & VI & Coletor e número & $\mathrm{D}$ & CL & $\mathrm{TF}$ \\
\hline $\begin{array}{l}\text { ARALIACEAE } \\
\text { Schefflera morototoni (Aubl.) } \\
\text { Maguire, Steyerm. \& Frodin }\end{array}$ & 10 & 0,60 & 0,44 & 1,02 & 2,06 & L.M.Nascimento 245 & $\mathrm{P}$ & $\mathrm{C}$ & macrófila \\
\hline $\begin{array}{l}\text { BOMBACACEAE } \\
\text { Eriotheca crenulaticalyx A. Robyns }\end{array}$ & 124 & 7,48 & 15,4 & 5,97 & 28,85 & L.M.Nascimento 195 & $\mathrm{C}$ & $\mathrm{C}$ & mesófila \\
\hline $\begin{array}{l}\text { BORAGINACEAE } \\
\text { Cordia sellowiana Cham. }\end{array}$ & 5 & 0,30 & 0,31 & 0,73 & 1,34 & L.M.Nascimento 174 & $\mathrm{P}$ & $\mathrm{S}$ & mesófila \\
\hline $\begin{array}{l}\text { CAESALPINIACEAE } \\
\text { Copaifera trapezifolia Hayne }\end{array}$ & 119 & 7,18 & 16,60 & 5,82 & 29,60 & L.M.Nascimento 412 & $\mathrm{C}$ & $\mathrm{C}$ & micrófila \\
\hline $\begin{array}{l}\text { CARICACEAE } \\
\text { Jacaratia dodecaphylla (Vell.) A. DC. } \\
\text { CELASTRACEAE }\end{array}$ & 1 & 0,06 & 0,05 & 0,15 & 0,25 & L.M.Nascimento 469 & $\mathrm{C}$ & $\mathrm{C}$ & mesófila \\
\hline $\begin{array}{l}\text { Maytenus erythroxylon Reissek } \\
\text { COMBRETACEAE }\end{array}$ & 13 & 0,78 & 0,12 & 1,60 & 2,51 & L.M.Nascimento 122 & $\mathrm{P}$ & $S$ & micrófila \\
\hline $\begin{array}{l}\text { Buchenavia capitata (Vahl) Eichler } \\
\text { ERYTHROXYLACEAE }\end{array}$ & 10 & 0,60 & 2,34 & 1,31 & 4,26 & L.M.Nascimento 320 & $\mathrm{C}$ & $\mathrm{S}$ & micrófila \\
\hline Erythroxylum blanchetii O. E. Schulz & 3 & 0,18 & 0,02 & 0,44 & 0,64 & A.G.Silva 12 & $\mathrm{P}$ & $S$ & micrófila \\
\hline $\begin{array}{l}\text { EUPHORBIACEAE } \\
\text { Sebastiania sp. }\end{array}$ & 1 & 0,06 & 0,01 & 0,15 & 0,22 & A.G.Silva 246 & $\mathrm{P}$ & $S$ & micrófila \\
\hline $\begin{array}{l}\text { FABACEAE } \\
\text { Machaerium angustifolium Vogel } \\
\text { Pterocarpus violaceus Vogel } \\
\text { Fabaceae sp. }\end{array}$ & $\begin{array}{r}2 \\
7 \\
22\end{array}$ & $\begin{array}{l}0,12 \\
0,42 \\
1,33\end{array}$ & $\begin{array}{l}0,08 \\
1,08 \\
0,86\end{array}$ & $\begin{array}{l}0,29 \\
1,02 \\
1,6\end{array}$ & $\begin{array}{l}0,49 \\
2,52 \\
3,79\end{array}$ & $\begin{array}{l}\text { L.M.Nascimento } 411 \\
\text { L.M.Nascimento } 351 \\
\text { L.M.Nascimento } 271\end{array}$ & $\begin{array}{l}\mathrm{P} \\
\mathrm{P} \\
\mathrm{C}\end{array}$ & $\begin{array}{l}\mathrm{C} \\
\mathrm{C} \\
\mathrm{C}\end{array}$ & $\begin{array}{l}\text { micrófila } \\
\text { mesófila } \\
\text { mesófila }\end{array}$ \\
\hline $\begin{array}{l}\text { FLACOURTIACEAE } \\
\text { Banara brasiliensis (Schott) Benth. } \\
\text { Casearia sylvestris } \mathrm{Sw} . \\
\text { Casearia } \text { sp. } 1 \\
\text { Casearia } \text { sp. } 2\end{array}$ & $\begin{array}{r}15 \\
9 \\
18 \\
3\end{array}$ & $\begin{array}{l}0,91 \\
0,54 \\
1,09 \\
0,18\end{array}$ & $\begin{array}{l}0,39 \\
0,30 \\
0,50 \\
1,18\end{array}$ & $\begin{array}{l}1,60 \\
1,02 \\
2,04 \\
0,44\end{array}$ & $\begin{array}{l}2,90 \\
1,86 \\
3,62 \\
1,80\end{array}$ & $\begin{array}{l}\text { L.M.Nascimento } 290 \\
\text { L.M.Nascimento } 176 \\
\text { L.M.Nascimento } 373 \\
\text { L.M.Nascimento } 388\end{array}$ & $\begin{array}{l}P \\
P \\
P \\
P\end{array}$ & $\begin{array}{l}S \\
S \\
S \\
S\end{array}$ & $\begin{array}{l}\text { micrófila } \\
\text { micrófila } \\
\text { micrófila } \\
\text { micrófila }\end{array}$ \\
\hline $\begin{array}{l}\text { LAURACEAE } \\
\text { Ocotea } \text { aff. elegans } \mathrm{Mez} \\
\text { Ocotea } \text { sp. }\end{array}$ & $\begin{array}{l}46 \\
22\end{array}$ & $\begin{array}{l}2,78 \\
1,33\end{array}$ & $\begin{array}{l}1,94 \\
1,05\end{array}$ & $\begin{array}{l}4,22 \\
2,47\end{array}$ & $\begin{array}{l}8,93 \\
4,85\end{array}$ & $\begin{array}{l}\text { A.G.Silva } 291 \\
\text { A.G.Silva } 242\end{array}$ & $\begin{array}{l}P \\
P\end{array}$ & $\begin{array}{l}S \\
S\end{array}$ & $\begin{array}{l}\text { micrófila } \\
\text { micrófila }\end{array}$ \\
\hline $\begin{array}{l}\text { MALPIGHIACEAE } \\
\text { Byrsonima } \text { cf. crispa A. Juss. } \\
\text { Byrsonima cf. pedunculata A. Juss. } \\
\text { Byrsonima nitidifolia A. Juss. }\end{array}$ & $\begin{array}{r}8 \\
1 \\
16\end{array}$ & $\begin{array}{l}0,48 \\
0,06 \\
0,97\end{array}$ & $\begin{array}{l}0,57 \\
0,01 \\
0,94\end{array}$ & $\begin{array}{l}1,02 \\
0,15 \\
1,60\end{array}$ & $\begin{array}{l}2,07 \\
0,21 \\
3,51\end{array}$ & $\begin{array}{l}\text { L.M.Nascimento } 212 \\
\text { L.M.Nascimento } 478 \\
\text { A.M.Silva } 51\end{array}$ & $\begin{array}{l}P \\
P \\
P\end{array}$ & $\begin{array}{l}S \\
S \\
S\end{array}$ & $\begin{array}{l}\text { notófila } \\
\text { micrófila } \\
\text { micrófila }\end{array}$ \\
\hline $\begin{array}{l}\text { MELASTOMATACEAE } \\
\text { Miconia cf. minutiflora (Bonpl.) DC. }\end{array}$ & 3 & 0,18 & 0,04 & 0,29 & 0,51 & L.M.Nascimento 470 & $\mathrm{P}$ & $\mathrm{S}$ & micrófila \\
\hline $\begin{array}{l}\text { MELIACEAE } \\
\text { Trichilia emarginata (Turcz.) C. DC. }\end{array}$ & 3 & 0,18 & 0,05 & 0,44 & 0,67 & L.M.Nascimento 471 & $\mathrm{P}$ & $\mathrm{C}$ & notófila \\
\hline $\begin{array}{l}\text { MIMOSACEAE } \\
\text { Albizia polycephala (Benth.) Killip. } \\
\text { ex Record }\end{array}$ & 1 & 0,06 & 0,01 & 0,15 & 0,21 & L.M.Nascimento 472 & $\mathrm{P}$ & $\mathrm{C}$ & notófila \\
\hline $\begin{array}{l}\text { Inga marginata Willd. } \\
\text { Inga subnuda Satzm. ex Benth. subsp. }\end{array}$ & 47 & 2,84 & 2,15 & 3,06 & 8,05 & L.M.Nascimento 109 & $\mathrm{C}$ & $\mathrm{C}$ & mesófila \\
\hline $\begin{array}{l}\text { subnuda } \\
\text { MORACEAE }\end{array}$ & 5 & 0,30 & 0,12 & 0,73 & 1,15 & A.G.Silva 157 & $\mathrm{P}$ & $\mathrm{C}$ & mesófila \\
\hline Brosimum guianensis (Aubl.) Huber & 2 & 0,12 & 0,05 & 0,29 & 0,46 & L.M.Nascimento 385 & $\mathrm{P}$ & $\mathrm{S}$ & micrófila \\
\hline Ficus sp. & 1 & 0,06 & 0,01 & 0,15 & 0,21 & L.M.Nascimento 384 & $\mathrm{C}$ & $\mathrm{S}$ & $\begin{array}{l}\text { notófila } \\
\text { continua }\end{array}$ \\
\hline
\end{tabular}


continuação

\begin{tabular}{|c|c|c|c|c|c|c|c|c|c|}
\hline Família/Espécie & $\mathrm{N}$ & DR & DoR & FR & VI & Coletor e número & $\mathrm{D}$ & $\mathrm{CL}$ & TF \\
\hline \multicolumn{10}{|l|}{ MYRSINACEAE } \\
\hline Myrsine guianensis (Aubl.) Kuntze & 21 & 1,27 & 0,57 & 2,33 & 4,16 & L.M.Nascimento 152 & $\mathrm{P}$ & $\mathrm{S}$ & notófila \\
\hline \multicolumn{10}{|l|}{ MYRTACEAE } \\
\hline Eugenia aff. citrifolia Poir. & 30 & 1,81 & 0,55 & 3,35 & 5,71 & L.M.Nascimento 308 & $\mathrm{P}$ & S & micrófila \\
\hline Eugenia aff. florida DC. & 7 & 0,42 & 0,17 & 0,87 & 1,46 & L.M.Nascimento 296 & $\mathrm{P}$ & S & micrófila \\
\hline Eugenia cf. mimus Mc Vaugh & 15 & 0,91 & 0,24 & 1,31 & 2,46 & L.M.Nascimento 209 & $\mathrm{P}$ & $\mathrm{S}$ & micrófila \\
\hline \multicolumn{10}{|l|}{ Marlierea clausseniana (O. Berg.) } \\
\hline Kiaersk. & 36 & 2,17 & 0,54 & 2,62 & 5,33 & L.M.Nascimento 223 & $\mathrm{P}$ & $\mathrm{S}$ & micrófila \\
\hline Myrcia amazonica DC. & 7 & 0,42 & 0,35 & 1,02 & 1,79 & L.M.Nascimento 135 & $\mathrm{P}$ & $\mathrm{S}$ & micrófila \\
\hline Myrcia sylvatica (G. Mey.) DC. & 2 & 0,12 & 0,02 & 0,29 & 0,43 & L.M.Nascimento 137 & $\mathrm{P}$ & $S$ & micrófila \\
\hline Plinia sp. & 54 & 3,26 & 1,35 & 3,64 & 8,25 & L.M.Nascimento 446 & $\mathrm{P}$ & S & micrófila \\
\hline Myrtaceae sp. 1 & 4 & 0,24 & 0,05 & 0,58 & 0,87 & L.M.Nascimento 447 & $\mathrm{P}$ & S & notófila \\
\hline Myrtaceae sp. 2 & 6 & 0,36 & 0,13 & 0,58 & 1,07 & L.M.Nascimento 448 & $\mathrm{P}$ & S & micrófila \\
\hline Myrtaceae sp. 3 & 17 & 1,03 & 0,63 & 1,75 & 3,41 & L.M.Nascimento 449 & $\mathrm{P}$ & S & notófila \\
\hline Myrtaceae sp. 4 & 5 & 0,30 & 0,05 & 0,73 & 1,08 & L.M.Nascimento 462 & $\mathrm{P}$ & S & micrófila \\
\hline Myrtaceae sp. 5 & 2 & 0,12 & 0,01 & 0,29 & 0,43 & L.M.Nascimento 467 & $\mathrm{P}$ & $S$ & micrófila \\
\hline \multicolumn{10}{|l|}{ NYCTAGINACEAE } \\
\hline Guapira nitida (Schmidt) Lundell & 433 & 26,13 & 22,42 & 7,28 & 55,83 & L.M.Nascimento 300 & $\mathrm{P}$ & $\mathrm{S}$ & micrófila \\
\hline \multicolumn{10}{|l|}{ OCHNACEAE } \\
\hline \multicolumn{10}{|l|}{ Ouratea aff. castaneaefolia (DC.) } \\
\hline Engler & 13 & 0,78 & 0,15 & 1,46 & 2,39 & L.M.Nascimento 347 & $\mathrm{P}$ & $\mathrm{S}$ & micrófila \\
\hline \multicolumn{10}{|l|}{ PROTEACEAE } \\
\hline Roupala paulensis Sleumer & 23 & 1,39 & 0,25 & 2,33 & 3,97 & L.M.Nascimento 418 & $\mathrm{P}$ & $\mathrm{S}$ & notófila \\
\hline \multicolumn{10}{|l|}{ RUBIACEAE } \\
\hline $\begin{array}{l}\text { Amaioua cf. guianensis Aubl. } \\
\text { Guettarda viburnoides Cham. \& }\end{array}$ & 48 & 2,90 & 0,83 & 3,64 & 7,37 & L.M.Nascimento 272 & $\mathrm{P}$ & $\mathrm{S}$ & notófila \\
\hline Schltdl. & 3 & 0,18 & 0,08 & 0,44 & 0,70 & L.M.Nascimento 242 & $\mathrm{C}$ & S & notófila \\
\hline \multicolumn{10}{|l|}{ Posoqueria latifolia (Rudge) Roem. } \\
\hline \& Schult. & 19 & 1,15 & 0,31 & 1,60 & 3,06 & L.M.Nascimento 341 & $\mathrm{P}$ & $\mathrm{S}$ & notófila \\
\hline Psychotria sessilis (Vell.) Müll. Arg. & 3 & 0,18 & 0,02 & 0,29 & 0,49 & L.M.Nascimento 162 & $\mathrm{P}$ & S & micrófila \\
\hline Rudgea jacobinensis Müll. Arg. & 6 & 0,36 & 0,21 & 0,58 & 1,15 & L.M.Nascimento 389 & $\mathrm{C}$ & $\mathrm{S}$ & micrófila \\
\hline \multicolumn{10}{|l|}{ SAPINDACEAE } \\
\hline Cupania oblongifolia Mart. & 8 & 0,48 & 0,89 & 0,87 & 2,24 & A.G.Silva 156 & $\mathrm{P}$ & $\mathrm{C}$ & mesófila \\
\hline Cupania revoluta Radlk. & 9 & 0,54 & 0,18 & 1,31 & 2,03 & L.M.Nascimento 149 & $\mathrm{P}$ & $\mathrm{C}$ & mesófila \\
\hline Dodonea viscosa (L.) Jacq. & 1 & 0,06 & 0,01 & 0,15 & 0,22 & L.M.Nascimento 150 & $\mathrm{P}$ & $\mathrm{S}$ & micrófila \\
\hline Matayba sp. & 4 & 0,24 & 0,22 & 0,58 & 1,05 & A.M. da Silva 47 & $\mathrm{P}$ & $\mathrm{C}$ & mesófila \\
\hline \multicolumn{10}{|l|}{ SAPOTACEAE } \\
\hline Manilkara rufula (Miq.) H. J. Lam. & 119 & 7,18 & 9,91 & 6,70 & 23,79 & L.M.Nascimento 311 & $\mathrm{C}$ & $\mathrm{S}$ & micrófila \\
\hline \multicolumn{10}{|l|}{ SIMAROUBACEAE } \\
\hline Picramnia gardneri Planch. & 5 & 0,30 & 0,04 & 0,44 & 0,78 & L.M.Nascimento 234 & $\mathrm{P}$ & $\mathrm{C}$ & micrófila \\
\hline \multicolumn{10}{|l|}{ SOLANACEAE } \\
\hline Brunfelsia uniflora (Pohl) D. Don. & 2 & 0,12 & 0,11 & 0,29 & 0,52 & L.M.Nascimento 164 & $\mathrm{P}$ & $\mathrm{S}$ & micrófila \\
\hline \multicolumn{10}{|l|}{ SYMPLOCACEAE } \\
\hline Symplocos nitens (Pohl) Benth. & 2 & 0,12 & 0,23 & 0,29 & 0,64 & L.M.Nascimento 230 & $\mathrm{P}$ & $\mathrm{S}$ & micrófila \\
\hline \multicolumn{10}{|l|}{ VERBENACEAE } \\
\hline Vitex rufescens A. Juss. & 1 & 0,06 & 0,01 & 0,15 & 0,22 & A.G.Silva 185 & $\mathrm{C}$ & $\mathrm{C}$ & mesófila \\
\hline \multicolumn{10}{|l|}{ Família não identificada } \\
\hline Não identificada & 1 & 0,06 & 0,03 & 0,15 & 0,23 & L.M.Nascimento 477 & $\mathrm{P}$ & $S$ & micrófila \\
\hline
\end{tabular}


relativa, ocorrendo em todas as parcelas, seguida por Copaifera trapezifolia (7,2 e 16,6\%) e Eriotheca crenulaticalyx (7,5 e 15,4\%).

Em termos de dominância relativa, é marcante a dominância de Copaifera trapezifolia (Caesalpiniaceae), tanto na classe de menor altura (1,3 a $4 \mathrm{~m}$ ), quanto acima dos $19 \mathrm{~m}$. Outras como Manilkara rufula (Sapotaceae), Eriotheca crenulaticalyx (Bombacaceae) e Aspidosperma cf. parvifolium (Apocynaceae) tendem a aumentar sua dominância relativa acima dos $13 \mathrm{~m}$, esta última ocupando as maiores classes de altura, juntamente com C. trapezifolia. Embora Guapira nitida (Nyctaginaceae) ocorra praticamente em todas as classes de altura, predomina entre 7 e $13 \mathrm{~m}$. Abaixo de $13 \mathrm{~m}$ de altura cabe destacar Amaioua cf. guianensis (Rubiaceae), Plinia sp. (Myrtaceae) e Ocotea aff. elegans (Lauraceae) (figura 2).

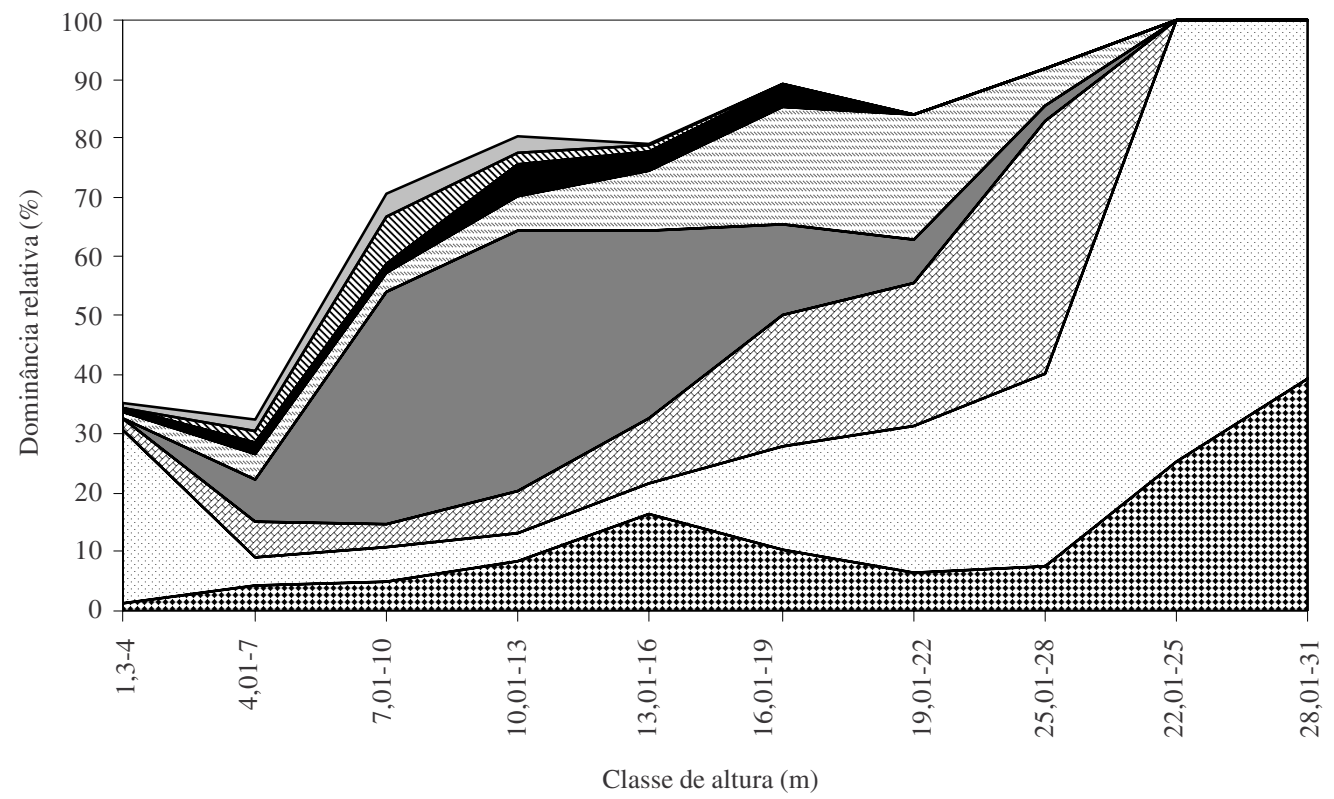

Figura 2. Distribuição da dominância relativa por espécie em intervalos de $3 \mathrm{~m}$, num fragmento de floresta estacional montana no Município de Brejo da Madre de Deus, Pernambuco. ( $\square=$ Plinia sp; $\mathbb{\mathbb { Q }}=$ Ocotea aff. elegans; $\square=$ Inga marginata $;$ 目 Manilkara rufula $; \square=$ Guapira nitida; $;=$ Eriotheca crenulaticalyx; $;=$ Copaifera trapezifolia; $;=$ Aspidosperma parvifolium; $\square=$ outras 54 espécies).

Figure 2. Distribution of the relative dominance per specie in intervals of $3 \mathrm{~m}$, in a seasonal montane forest fragment at Brejo

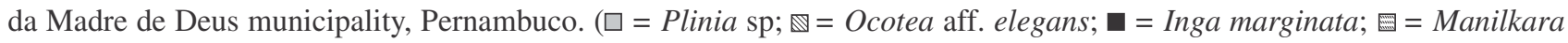

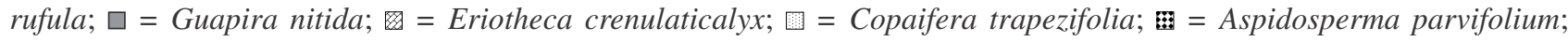
$\square=$ outras 54 espécies).

Tamanho, deciduidade e composição do limbo foliar Quanto ao tamanho, houve o predomínio de espécies com folhas micrófilas (63\%), seguida por indivíduos de mesófilas e notófilas (14,3 e 9,7\%). Espécies micrófilas preponderaram em quase todas as classes de altura, com exceção da classe 19,1 a 22 m (dossel), onde houve domínio de macrófilas e mesófilas (figura 3A).

Cerca de $80 \%$ das espécies são perenifólias, predominando nas classes de altura abaixo dos $22 \mathrm{~m} \mathrm{e}$, acima disto, se sobressaem as espécies decíduas, como Aspidosperma cf. parvifolium, Copaifera trapezifolia, Eriotheca crenulaticalyx e Manilkara rufula (figura 3B).

Quanto à composição do limbo, cerca de $72 \%$ das espécies apresentam folhas simples (figura 3C). Exceções marcantes ocorrem na classe de altura de 4,1 a $7 \mathrm{~m}$, especialmente pela presença de representantes de Mimosaceae e Fabaceae, e acima dos $22 \mathrm{~m}$, pela grande densidade de indivíduos adultos de espécies emergentes (Copaifera trapezifolia e Eriotheca crenulaticalyx). Similaridade - A análise de agrupamento realizada com base na densidade relativa das espécies presentes em 10 levantamentos quantitativos, inclusive a área de estudo, individualizou apenas as áreas de florestas montanas mais orientais do estado (Ferraz et al. 2003, Rodal \& Nascimento 2006). Nos outros levantamentos não foi possível individualizar grupos. A área de estudo foi mais relacionada com as florestas ombrófilas, independente da altitude (Barbosa 1996, Tavares et al. 2000, Siqueira et al. 2001, Ferraz \& Rodal 2006, Silva \& Rodal dados não publicados), ver figura 4. 
A

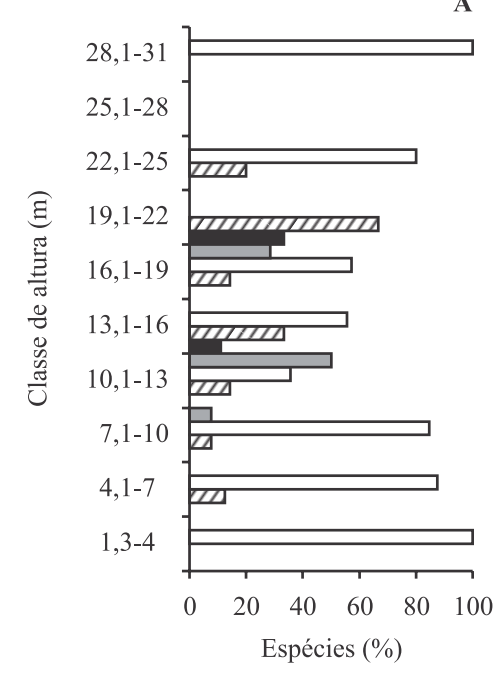

B

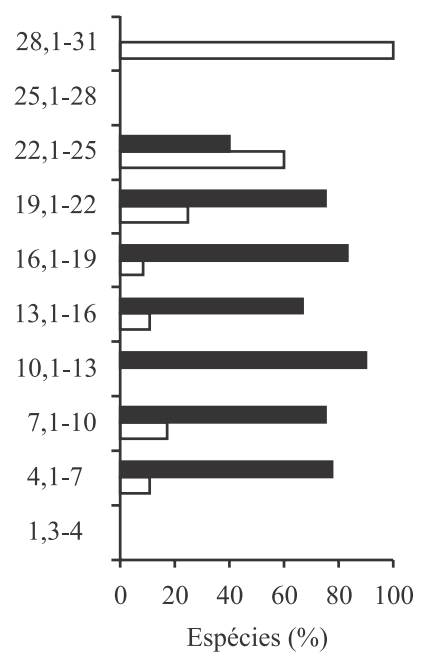

C

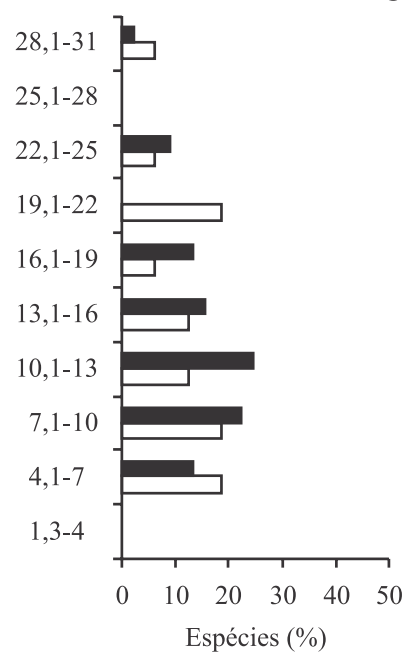

Figura 3. Distribuição da percentagem do número de espécies, de acordo com (A) tamanho da folha ( $\square=$ micrófila; $\square=$ notófila; $\mathbb{\nabla}=$ mesófila; $\boldsymbol{\square}=$ macrófila), (B) deciduidade ( $\boldsymbol{\square}$ = perenifólia; $\square$ = caducilófia) e (C) composição do limbo ( $\square$ = simples; $\square=$ composto) em intervalos de classe de $3 \mathrm{~m}$, num fragmento de floresta estacional montana no Município de Brejo da Madre de Deus, Pernambuco.

Figure 3. Distribution of the percentage of the species number, according to the (A) leaf size ( $\square=$ microphyll; $\square=$ notophyll; $\mathbb{\square}=$ mesophyll; $\boldsymbol{\square}=$ macrophyll $)$, (B) the deciduousness $(\boldsymbol{\square}=$ evergreen; $\square=$ deciduous $)$ and (C) the lamina type ( $\square$ = simple; $\square=$ compound) in class intervals of $3 \mathrm{~m}$, in a seasonal montane forest fragment at Brejo da Madre de Deus municipality, Pernambuco.

Informação restante $(\%)$

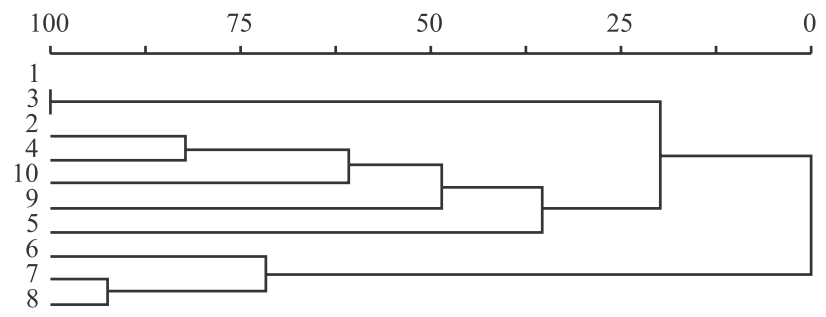

Figura 4. Dendrograma de similaridade vegetacional entre a área de estudo e nove levantamentos quantitativos de florestas de Pernambuco e Paraíba (1 = Barbosa 1996; 2 = Silva \& Rodal dados não publicados; 3 = Siqueira et al . 2001; 4 = Tavares et al. 2000; 5 = área de estudo; $6=$ Rodal \& Nascimento 2006; 7 = Ferraz et al. 2003, 1.100 m; $8=$ Ferraz et al. 2003, 900 m; $9=$ Andrade \& Rodal 2004; $10=$ Ferraz \& Rodal 2006; 1-3 = floresta ombrófilas de terras baixas; 4, 10 = floresta ombrófila montana; 5-8 = floresta estacional montana; 9 = floresta estacional de terras baixas).

Figure 4. Vegetational dendrogram similarity between the study area and nine quantitative surveys of forest from Pernambuco and Paraíba States (1 = Barbosa 1996; 2 = Silva \& Rodal no publish; 3 = Siqueira et al. 2001; 4 = Tavares et al . 2000; $5=$ study area; $6=$ Rodal $\&$ Nascimento 2006; $7=$ Ferraz et al. 2003, $1.100 \mathrm{~m} ; 8=$ Ferraz et al. 2003, $900 \mathrm{~m} ; 9$ = Andrade \& Rodal 2004; $10=$ Ferraz \& Rodal 2006; 1-3 = rain tropical lowland forest; $4,10=$ rain tropical montane forest; $5-8=$ seasonal montane forest; 9 = seasonal lowland forest).

\section{Discussão}

Fisionomia - A floresta montana de Brejo da Madre de Deus apresentou densidade similar às registradas nos levantamentos em florestas montanas e de terras baixas, quer sejam elas estacionais ou ombrófilas, corroborando com a tendência observada por Lieberman et al. (1996) num gradiente de 100 a 2.600 m de altitude na Costa Rica, e Smith \& Killeen (1995), comparando duas florestas na Bolívia, uma de terras baixas (270 m) e outra montana (900 m).

As florestas de terras baixas analisadas por Barbosa (1996), Andrade \& Rodal (2004) e Silva \& Rodal (dados não publicados) apresentaram densidades inferiores à de outros levantamentos em Pernambuco, provavelmente pelo fato de serem florestas urbanas, portanto muito expostas à perturbação antrópica.

Apesar de não haver diferenças estatísticas quanto à área basal das florestas de terras baixas e montanas, observa-se uma tendência de aumento de área basal com a altitude, semelhante ao encontrado por Lieberman et al. (1996) e Smith \& Killeen (1995).

Para os trabalhos da região, que adotaram o mesmo critério de inclusão utilizado neste estudo, os valores máximos de altura e diâmetro mostraram uma tendência de aumento com a elevação da altitude, diferentemente do observado por Lieberman et al. (1996), num gradiente 
altitudinal $(1.000$ a $2.600 \mathrm{~m})$, onde as maiores alturas ocorreram nas menores altitudes, permanecendo o diâmetro constante.

O fato das análises estatísticas da distribuição do número de indivíduos por classe de altura e área basal, indicar que não há diferença significativa entre a área de estudo e as florestas analisadas de Pernambuco, com exceção de uma floresta estacional montana (Rodal \& Nascimento 2006), pode ser explicado por ocorrência desta floresta sobre solos arenosos bastante profundos, ao contrário das demais florestas estacionais montanas, onde os solos são em geral rasos e bastante pedregosos. Estrutura - De acordo com Gentry (1995) e Richards (1996) a riqueza de espécies em florestas tropicais de todos os continentes decresce com o aumento da sazonalidade e aumenta com o incremento da precipitação anual. Ao compararmos as florestas montanas de Pernambuco, nota-se que à medida que as florestas vão ficando mais secas há uma diminuição considerável na riqueza e na diversidade, onde a razão espécie/diversidade variou de 91,0/3,60 na floresta ombrófila estudada por Tavares et al. (2000) a 49,0/2,71 na floresta estacional analisada por Rodal \& Nascimento (2006).

Famílias ricas em espécies arbóreas ocorrendo em florestas de terras baixas, como Leguminosae, Sapotaceae, Burseraceae, Chrysobalanaceae e Bignoniaceae, tendem a ser pobremente representadas nas florestas neotropicais montanas, isto é, em altitudes maiores que 600 m (Gentry 1988). Esse padrão não foi registrado no gradiente altitudinal das terras baixas a montanas de Pernambuco, onde a riqueza daquelas famílias está mais relacionada disponibillidade hídrica local para as plantas que a altitude propriamente dita (Ferraz et al. 1998, Tavares et al. 2000, Andrade \& Rodal 2004, Ferraz \& Rodal 2006, Rodal \& Nascimento 2006).

Em termos de famílias, vale destacar que Leguminosae (sensu Engler) tem elevada importância estrutural nas terras baixas (Siqueira et al. 2001, Andrade \& Rodal 2004), sendo pobremente representada nas florestas montanas, especialmente as mais secas (Ferraz et al. 2003, Rodal \& Nascimento 2006, este trabalho). Com relação as espécies, não ocorreu nenhum padrão marcante, embora Andrade-Lima $(1961,1964)$ tenha observado que espécies estruturalmente importantes na área, como Manilkara rufula e Copaifera trapezifolia podem ser indicadoras das florestas montanas de Pernambuco.

Das espécies estruturalmente importantes no estrato inferior (abaixo de $13 \mathrm{~m}$ ) podemos citar: Amaioua cf. guianensis (Rubiaceae), Plinia sp. (Myrtaceae) e Ocotea aff. elegans (Lauraceae), enquanto no dossel (acima de $19 \mathrm{~m}$ ) destacam-se Guapira nitida (Nyctaginaceae),
Manilkara rufula (Sapotaceae), Eriotheca crenulaticalyx (Bombacaceae) e Aspidosperma cf. parvifolium (Apocynaceae). Apesar de Guapira nitida ser uma espécie característica do dossel, teve elevada densidade nos andares mais baixos da floresta, imprimindo um aspecto visual mais denso do sub-dossel.

No caso das espécies estruturamente mais importantes acima dos $22 \mathrm{~m}$ (emergentes) podemos destacar, Copaifera trapezifolia (Caesalpiniaceae) e Eriotheca crenulaticalyx (Bombacaceae). Vale destacar que a primeira ocorre com elevada densidade, frequiência e dominância em todos os andares da floresta.

Tamanho, deciduidade e composição do limbo - De um modo geral, plantas de florestas neotropicais exibem uma diminuição da área foliar com o aumento da altitude, mudando da predominância da classe mesófila em florestas de terras baixas para notófila e micrófilas em florestas montanas (Richards 1996). Esta tendência também pode ser observada nos trabalhos de Grubb et al. (1963), Grubb (1977) e Madsen \& Øllgaard (1994) em florestas do Equador. Além disso, Webb (1968) mostrou ainda que, independente da altitude, quanto mais secas as florestas, menor o tamanho foliar. Os resultados encontrados em Pernambuco reforçam as idéias desses autores uma vez que a área de estudo apresentou espécies com áreas foliares menor que da floresta estacional de terras baixas de São Lourenço da Mata (Andrade \& Rodal 2004), onde predominam notófilas (tabela 4).

Diferentemente do padrão referido por Walter (1971) e Popma et al. (1988), que relatam que o tamanho das folhas tende a diminuir do sub-dossel para o dossel, os resultados das florestas estacionais de Pernambuco (Andrade \& Rodal 2004, este trabalho) mostram que há o predomínio de micrófilas no sub-dossel e de macrófilas e mesófilas no dossel. Possíveis explicações para este padrão inverso necessitam de estudos adicionais. No caso da área de estudo, podemos citar como macrófilas e mesófilas: Schefflera morototoni, Cupania oblongifolia, Eriotheca crenulaticalyx, Fabaceae sp.1 e Inga marginata.

Segundo Givnish (1984), as árvores dos extratos mais elevados tendem a apresentar caducifolia, uma vez que estão mais expostas à dessecação pelo vento e radiação solar que as dos menores estratos. Ainda de acordo com este autor, as árvores decíduas das florestas tropicais perdem sua folhagem durante a estação seca devido à necessidade de reduzir a transpiração e a respiração. Este fato também foi observado na área de estudo.

Nas florestas tropicais, folhas simples são mais comuns em florestas montanas que em terras baixas (Givnish 1978). Walter (1971) observou que a predominância de folhas simples em florestas montanas resulta de processos 


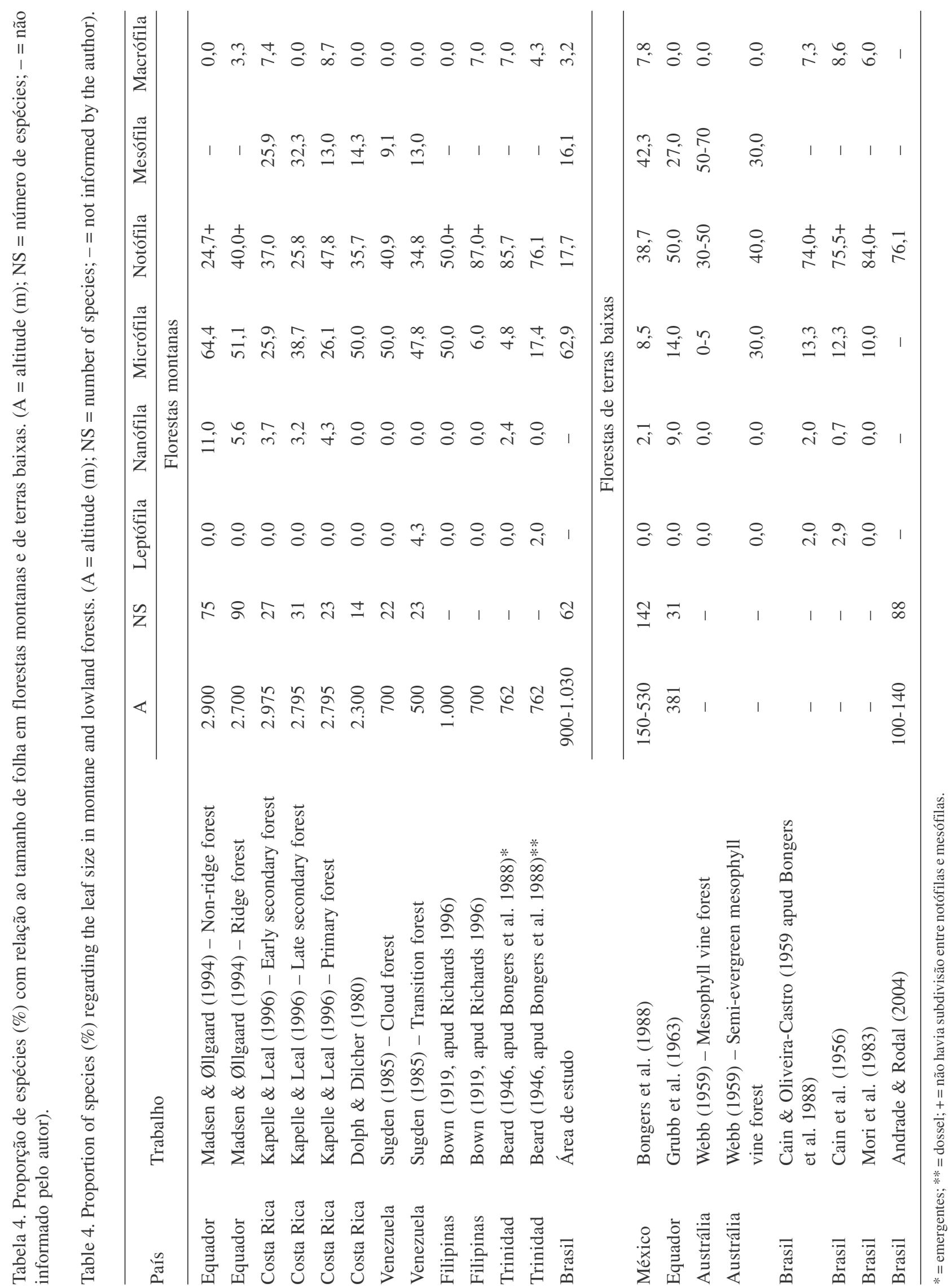


adaptativos à diminuição da temperatura e da intensidade luminosa e aumento da umidade e precipitação. O padrão acima referido por Givnish (1978) não ocorreu na área de estudo e na analisada por Andrade \& Rodal (2004), indicando que essas características (folhas simples e compostas) não distinguem os dois tipos de floresta quanto ao relevo.

Embora predominem folhas simples, nota-se que a proporção de espécies arbóreas com folhas compostas aumenta com a altura e exposição em cada estrato, semelhante ao relatado por Cain et al. (1956). Além disso, Givnish (1978) observa que espécies lenhosas com folhas compostas são mais comuns em ambientes áridos, como desertos, savanas e florestas secas, sugerindo que folhas compostas podem ser uma adaptação para ambientes secos ou uma adaptação para um rápido crescimento vertical.

Similaridade - Os resultados da análise de grupamento indicam que a proximidade geográfica tem forte influência na semelhança estrutural entre os levantamentos, uma vez que todas as florestas situadas no topo do Planalto da Borborema (áreas de estudo), na encosta ocidental desse planalto (Tavares et al. 2000, Ferraz \& Rodal 2006) e nas áreas próximas da costa atlântica (Barbosa 1996, Siqueira et al. 2001) se agrupam com níveis muito baixo de similaridade, indicando um possível gradiente. Este conjunto se individualiza claramente do grupo das florestas situadas em relevos residuais da depressão sertaneja (Rodal \& Nascimento 2006) e da encosta oriental da Borborema (Ferraz et al. 2003), revelando a influência da distância geográfica na distribuição das espécies, como foi observado por Oliveira Filho et al. (2006).

Agradecimentos - Ao CNPq pela concessão da bolsa de mestrado e pela bolsa de produtividade da segunda autora, à Fundação O Boticário de Proteção à Natureza (proc. 0345981) e ao WWF-Brasil (proc. 193-200), pelo apoio financeiro à pesquisa. Ao Sr. Reginaldo Araújo, proprietário da fazenda Bituri, por apoiar e permitir a realização deste estudo. Aos especialistas do Brasil e exterior (Celastraceae - R. M. Okano; Erythroxylaceae - M.I.B. Loiola; Lauraceae - Henk van der Werff; Myrtaceae - G. Barroso; Nyctaginaceae - A. Furlan; Rubiaceae - D. Zappi; Sapindaceae - M.S. Ferrucci e Simaroubaceae - W.W. Thomas), pela identificação dos materiais enviados. À conselheira Dra. Rejane M. Pimentel, à Dra. Margareth Sales, ao Dr. Everardo Sampaio, MSc. Alexandre G. Silva e Eudes Rafael (motorista), pela colaboração em diversas fases deste trabalho e a Adriano e Clemilson (mateiros locais), pelo auxílio no campo.

\section{Referências bibliográficas}

ANDRADE-LIMA, D. 1961. Tipos de floresta de Pernambuco. Anais da Associação dos Geógrafos Brasileiros 12:69-85.
ANDRADE-LIMA, D. 1964. Esboço fitoecológico de alguns brejos de Pernambuco. Instituto de Pesquisas Agronômicas de Pernambuco. Boletim Técnico 8:3-10.

ANDRADE, K.V.S.A. \& RODAL, M.J.N. 2004. Fisionomia e estrutura de um remanescente de floresta estacional semidecidual de terras baixas no nordeste do Brasil. Revista Brasileira de Botânica 27:463-474.

BARBOSA, M.R.V.B. 1996. Estudo florístico e fitossociológico da Mata do Buraquinho, remanescente de Mata Atlântica em João Pessoa, PB. Tese de doutorado, Universidade Estadual de Campinas, Campinas.

BONGERS, F., POPMA, J., CASTILLO, J.M. \& CARABIAS, J. 1988. Structure and floristic composition of the lowland rain forest of Los Tuxtlas, Mexico. Vegetatio 74:55-80.

CAIN, S.A., OLIVEIRA-CASTRO, G.M., PIRES, J.M. \& SILVA, N.T. 1956. Application of some phytosociological techniques to Brazilian rain forest. American Journal of Botany 43:911-941.

CRONQUIST, A. 1981. An integrated system of classification of flowering plants. Columbia University Press, New York.

DOLPH, G.E. \& DILCHER, D.L. 1980. Variation in leaf size with respect to climate in Costa Rica. Biotropica 12:91-99.

FERRAZ, E.M.N. \& RODAL, M.J.N. 2006. Caracterização fisionômica-estrutural de um remanescente de floresta ombrófila montana de Pernambuco, Brasil. Acta Botanica Brasilica 20:911-926.

FERRAZ, E.M.N., RODAL, M.J.N., SAMPAIO, E.V.S.B. \& PEREIRA, R. de C.A. 1998. Composição florística em trechos de vegetação de caatinga e brejo de altitude na região do Vale do Pajeú, Pernambuco. Revista Brasileira de Botânica 21:7-15.

FERRAZ, E.M.N., RODAL, M.J.N. \& SAMPAIO, E.V.S.B. 2003. Physiognomy and structure of vegetation along an altitudinal gradient. Phytocoenologia 33:71-92.

GENTRY, A.H. 1988. Changes in plant community diversity and floristic composition on environmental and geographical gradients. Annals of the Missouri Botanical Garden 75:1-34.

GENTRY, A.H. 1995. Diversity and floristic composition of neotropical dry forests. In Seasonally dry forests (S.H. Bullock, H.A. Mooney \& E. Medina, eds.). Cambridge University Press, Cambridge, p.146-194.

GIVNISH, T.J. 1978. On the adaptive significance of compound leaves, with particular reference to tropical trees. In Tropical trees as living systems (P.B. Tomlinson \& M.H. Zimmermann, eds.). Cambridge University Press, Cambridge, p.351-380.

GIVNISH, T.J. 1984. Leaf and canopy adaptations in tropical forests. In Physiological ecology of plants in the wet tropics (E. Medina, H.A. Mooney \& C. Vazquez-Yánes, eds.). W. Junk Publishers, The Hague, p.51-84. 
GRUBB, P.J., LLOYD, J.R.T., PENNINGTON, D. \& WHITMORE, T.C. 1963. A comparison of montane and lowland rain forest in Ecuador. The forest structure, physiognomy and floristic. Journal of Ecology 51:567-601.

GRUBB, P.J. 1977. Control of forest growth and distribution on wet tropical mountains. Annual Review of Ecology \& Systematics 8:83-107.

JACOMINE, P.K.T., CAVALCANTI, A.C., BURGOS, N., PESSOA, S.C.P. \& SILVEIRA, C.O. 1973. Levantamento exploratório - Reconhecimento de solos do Estado de Pernambuco. Boletim Técnico 26, SUDENE/DNPE, Recife.

KAPPELLE, M. \& LEAL, M.E. 1996. Changes in leaf morphology and foliar nutrient status along a successional gradient in a Costa Rican upper montane Quercus forest. Biotropica 28:331-344.

LIEBERMAN, D., LIEBERMAN, M., PERALTA, R. \& HARSHORN, E.G.S. 1996. Tropical forest structure and composition on a large-scale altitudinal gradient in Costa Rica. Journal of Ecology 84:137-152.

LYRA, A.L.R.T. 1982. Efeito do relevo na vegetação de duas áreas do Município do Brejo da Madre de Deus (PE). Dissertação de mestrado, Universidade Federal Rural de Pernambuco, Recife.

MADSEN, J.E. \& ØLLGAARD, B. 1994. Floristic composition, structure, and dynamics of an upper montane rain forest in Southern Ecuador. Nordic Journal of Botany 14:403423.

MCCUNE, B. \& MEFFORD, M.J. 1999. PC-ORD. Multivariate analysis of ecological data, version 4,14. MjM Software Design, Oregon.

MORI, S.A., BOOM, B.M., CARVALHO, A.M. \& SANTOS, T.S. 1983. Southern bahian moist forests. Botanical Review 49:155-232.

OLIVEIRA-FILHO, A.T., JARENKON, J.A. \& RODAL, M.J.N. 2006. Floristic relationships of seasonally dry forests of eastern South America based on tree species distribution patterns. In Neotropical savannas and dry forests: Plant diversity, biogeography and conservation. (R.T. Pennington, G.P. Lewis \& J.A. Ratter, orgs). CRC Press, Boca Raton, p.11-51.

POPMA, J., BONGERS, F. \& CASTILLO, J.M. 1988. Patterns in the vertical structure of the tropical lowland rain forest of Los Tuxtlas, Mexico. Vegetatio 74:81-91.

RAUNKIAER, C. 1934. Life forms of plants and statistical Plant Geography. Clarendon Press, Oxford.

RICHARDS, P.W. 1996. The tropical rain forest: an ecological study. $2^{\text {nd }}$ ed. University Press, Cambridge.

RODAL, M.J.N. \& NASCIMENTO, L.M. 2006. The arboreal component of a dry forest in Northeastern Brazil. Brazilian Journal of Biology 66:479-491
SHEPHERD, G.J. 1995. FITOPAC 2.0 - Manual do usuário. UNICAMP, Campinas.

SIQUEIRA, D.R., RODAL, M.J.N., SILVA, A.C.B. \& MELO, A.L. 2001. Physiognomy, structure and floristic in an area of Atlantic Forest in Northeast Brazil. In Life forms and dynamics in tropical forest (G. Gottsberger \& S. Liede, eds.). J. Cramer, Berlin, p.11-27.

SMITH, D.N. \& KILLEEN, T.J. 1995. A comparison of the structure and composition of montane and lowland tropical forest in the Serranía Pilón Laja, Beni, Bolívia. Missouri Botanical Garden, http://www.mobot.org/ MOBOT/research/bolívia/pilonarticle/welcome.htm (acesso em 20/10/2000).

SOKAL, R.R. \& ROHLF, F.J. 1979. Biometria: princípios y métodos estadísticos en la investigación biológica. $\mathrm{H}$. Blume, Madrid.

SUDGEN, A.M. 1985. Leaf anatomy in a Venezuelan montane forest. Botanical Journal of the Linnean Society 90:231-241.

TAVARES, M.C.G., RODAL, M.J.N., MELO, A.L. \& ARAÚJO, M.F.L. 2000. Fitossociologia do componente arbóreo de um trecho de Floresta Ombrófila Montana do Parque Ecológico João Vasconcelos Sobrinho, Caruaru, Pernambuco. Naturalia 26:243-270.

VASCONCELOS SOBRINHO, J. 1970. Os brejos de altitude e as matas serranas. In As regiões naturais do Nordeste, o meio e a civilização. Conselho de Desenvolvimento de Pernambuco, Recife, p.79-86.

VELOSO, H.P., RANGEL-FILHO, A.L.R. \& LIMA, J.C.A. 1991. Classificação da vegetação brasileira, adaptada a um sistema universal. IBGE - Departamento de Recursos Naturais e Estudos Ambientais, Rio de Janeiro.

VOGELMANN, H.W. 1973. Fog precipitation in the cloud forests of eastern Mexico. BioScience 23:96-100.

WALTER, H. 1971. Ecology of tropical and subtropical vegetation. Oliver \& Boyd, Edinburgh.

WEBB, L.J. 1959. A physiognomic classification of Australian rain forests. Journal of Ecology 47:551-570.

WEBB, L.J. 1968. Environment relationships of the structural types of Australian rain forest vegetation. Ecology 49:296-311.

WEBSTER, G.L. 1995. The panorama of neotropical cloud forests. In Biodiversity and conservation of neotropical montane forests (S.P. Churchill, H. Balslev, E. Forero \& J.L. Luteyn, eds.). The New York Botanical Garden, New York, p.53-77.

WERGER, M.J.A. \& SPRANGERS, J.T.C. 1982. Comparison of floristic and structural classification of vegetation. Vegetatio 50:175-183. 